\title{
Clinical significance of the fleurette in retinoblastoma
}

\author{
DAVID SEVEL,* G. F. RÖHM, $†$ AND R. SEALY $\ddagger$
}

From the * Department of Ophthalmology, the $\uparrow$ Department of Pathology, and the $\ddagger$ Department of Radiotherapy, University of Cape Town, and Groote Schuur Hospital, South Africa

This communication deals with the prognostic significance ascribed to fleurette formation in retinoblastoma (Editorial, 1973), first described by T'so, Fine, and Zimmerman (1970a) and T'so, Zimmerman, and Fine (1970b).

A series of 67 eyes with retinoblastoma was gleaned from the Ocular-Tumour Clinic at Groote Schuur Hospital, Cape Town. The retinoblastomata had not been treated before enucleation with either chemotherapy or radiation; treated cases were excluded from the series.

The eyes were embedded in paraffin wax and from each block a section was cut, stained with haematoxylin and eosin, and examined by light microscopy.

Two of these eyes with retinoblastoma showed single cell photoreceptor elements, and in two there were well-formed fleurettes. One eye, with well-formed fleurettes, was examined by electron microscopy.

\section{Case reports}

Case r. A coloured boy aged 3 years presented with a left convergent squint of 3 months' duration.

\section{Examination}

Under general anaesthesia, a large, white, crenated mass was seen to involve the entire retina and to extend into the vitreous body. There was no anterior uveitis and the left eye was not enlarged. $X$-ray examination of the orbit showed no calcification and the optic foramen was not enlarged.

The right eye showed no abnormality and there was no family history of retinoblastoma.

\section{Treatment}

On March I, 1958, the left eye was enucleated.

Subsequent treatment included deep $x$-ray therapy to a total tumour dose of 2,500 rads over a 5-week period.

\section{Result}

The patient was discharged on April 23, 1958, and was lost to follow-up. Further inquiries revealed that the child had died of secondary metastases on August 25, 1958.

\section{Histological examination}

MAGROSCOPIC

The eye was $2 \mathrm{~cm}$. in diameter and on section it was found to be completely filled with a white soft 
granular neoplasm that had destroyed and replaced all the internal ocular structures. The optic nerve stump was $0 \cdot 6 \mathrm{~cm}$. long.

\section{MICROSCOPIC}

Retinoblastoma completely filled the eye and had destroyed and replaced the entire uveal tract and retina. The lens was not discernible in the section examined. There was superficial invasion of the sclera at many points and the optic nerve was infiltrated to the line of section.

The retinoblastoma showed areas of necrosis but no foci of calcification were noted. The major portion of the neoplasm consisted of closely-packed small undifferentiated cells which had scanty cytoplasm. In one area the neoplastic cells lay further apart, giving a spongy appearance, and at this site single cell photoreceptor elements were seen.

These photoreceptor elements had nuclei which appeared to be slightly larger than the nuclei of the cells of the rest of the retinoblastoma. The eosinophilic, bulbous cytoplasmic processes projected into the inter-cellular spaces.

Fleurette formation was not noted and rosettes were not present in the section.

Case 2. A coloured girl aged 5 years was first seen on November 27, 1967, with a I month history of a right leucocoria.

\section{Examination}

Under general anaesthesia, a white crenated mass was seen to involve almost the entire retina and it extended into the vitreous where seedling deposits were noted.

The eye was not enlarged.

$X$-ray examination of the orbit showed no calcification and the optic foramen was not enlarged.

Examination of the left eye showed no abnormality, and there was no family history of retinoblastoma.

\section{Treatment}

The right eye was enucleated on December 4, 1967.

Deep $x$-ray therapy was given to a maximum tumour dose of 3,840 rads over 28 days. During this treatment she received three injections of triethylenemelamine (TEM) to a dose of $0.7 \mathrm{mg} . / \mathrm{kg}$. body weight.

\section{Result}

The patient was last seen in September, 1972, and she was then well without evidence of local recurrence of the tumour in the orbit or of systemic metastases.

\section{Histological examination}

\section{MACR OSCOPIC}

The eye was $1 \cdot 9 \mathrm{~cm}$. in diameter and the optic nerve stump was $0.3 \mathrm{~cm}$. long.

A granular pale neoplasm was present which filled much of the vitreous body.

\section{MIGROSCOPIC}

An undifferentiated exoendophytic retinoblastoma was present in the posterior aspect of the eye. The involved retina was destroyed but the uveal tract was not invaded. There was no extension of the tumour along the optic nerve stump. There was an area within the retinoblastoma in which numerous large well-formed fleurettes were present.

These fleurettes (Figs I and 2) had nuclei that were similar to those of the rest of the neoplasm. From the nuclei many eosinophilic, interdigitating cytoplasmic processes projected through what appeared to be a membrane, into a large inter-cellular space. Here the processes fanned outwards into bulbous ends. Rosette formation and single cell photoreceptor cells were not noted. 


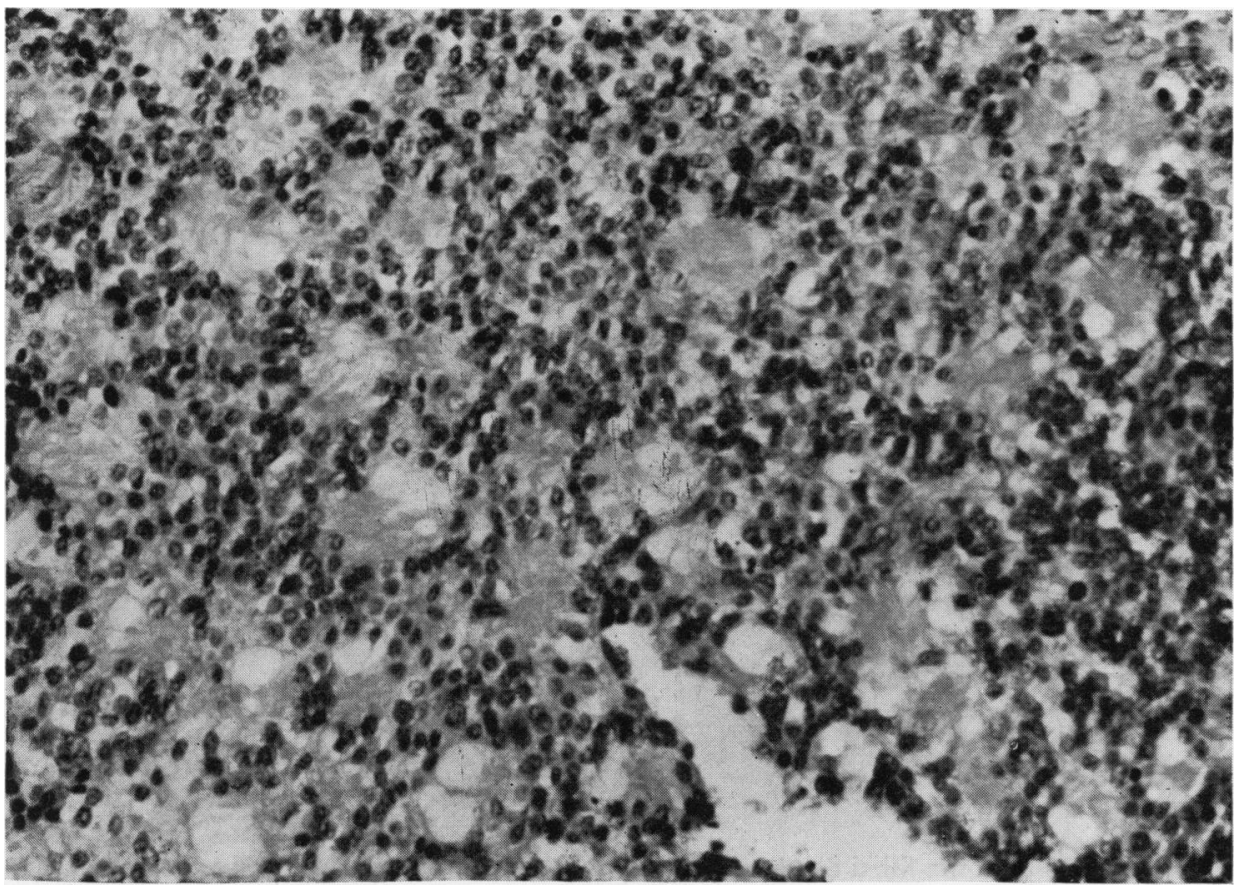

FIG. I Case 2. Large spaces are surrounded by nuclei. The spaces contain numerous eosinophilic cytoplasmic projections which constitute the fleurettes. Haematoxylin and eosin. $\quad \times 120$

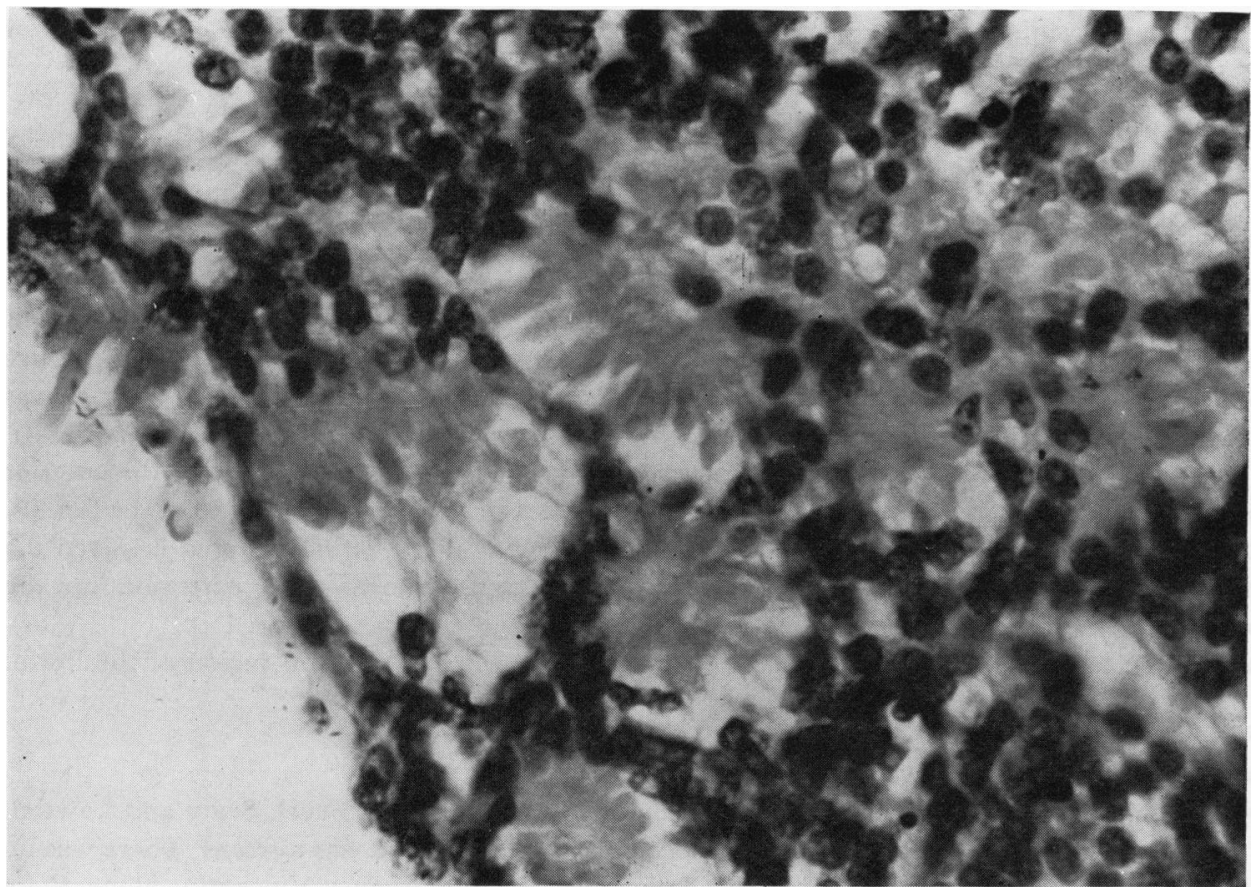

FIG. 2 Case 2. Well-formed large fleurettes are clearly seen in each intercellular space. Club-shaped photoreceptor cytoplasmic processes interdigitate and splay outwards to form a fleurette. Haematoxylin and eosin $\quad \times 300$ 
Case 3. A coloured girl aged $2 \frac{1}{2}$ years presented to a peripheral hospital on September 7, 1966, with a squint of 3 months' duration. She was subsequently assessed at the Eye Out Patients Department at Groote Schuur Hospital, and found to have a left divergent squint.

\section{Examination}

Under general anaesthesia, a large white cream-cheese like mass was observed to involve the entire retina. Occasional seedling deposits were present in the vitreous body. There were cells in the anterior chamber but no tumour deposits were noted. The eye was not enlarged.

$X$-ray examination of the orbit showed no calcification and the optic foramen was not enlarged.

Examination of the opposite eye showed no abnormality, and there was no family history of retinoblastoma.

\section{Treatment}

On October 24, 1966, the left eye was enucleated.

Subsequent therapy included deep $x$-ray therapy to a maximum tumour dose of 4,095 rads over 33 days and during this course three injections of $\mathrm{I} \cdot 3 \mathrm{ml}$. triethylenemelamine (TEM) were given.

\section{Histological examination}

MAGROSCOPIC

The eye was not available for examination.

\section{MIGROSGOPIC}

An endophytic retinoblastoma filled the vitreous body but had not invaded the iris or anterior chamber. Much of the retina was destroyed and neoplastic seedlings were noted in the uninvolved areas of the retina. The choroid was invaded at a number of sites by the retinoblastoma.

The retinoblastoma showed little necrosis. Areas with a loose and spongy appearance were noted at one site and single cell photo-receptor elements were observed. Their nuclei were enlarged and eosinophilic cytoplasmic processes projected into the inter-cellular spaces. Neither rosettes nor fleurettes could be found.

Case 4. A coloured boy aged $\mathrm{I} \frac{1}{2}$ years was first seen in the Eye Out Patients Department on May I 7, 1973, with a history of an enlarged eye over a 4-month period.

\section{Examination}

The left eye was found to be enlarged, the corneal diameter being $14 \mathrm{~mm}$. The anterior chamber was shallow because the iris was bowed forward. The pupil did not react to direct or consensual light stimulation. On funduscopy under general anaesthesia, a large white mass was seen to fill the entire posterior segment. New vessels were seen to course over the tumour. The intraocular pressure was raised to $45 \mathrm{~mm} . \mathrm{Hg}$ (applanation tonometer).

The right eye was of normal size, the cornea was clear and $10 \mathrm{~mm}$. in diameter, and the anterior chamber of normal depth. The lens was not cataractous and a clear view was obtained of the fundus. A white flat mass $(3 \times 4 \mathrm{~mm}$.) with a crenated surface was noted. The retinoblastoma involved the mid-periphery of the retina and extended from the 7 to 2 o'clock. There was no extension into the vitreous.

A radioactive scan $\left(\mathbf{I}^{131}\right)$ showed an increased uptake over the right frontal region of the brain.

\section{Treatment}

On May 24, 1973, the left eye was enucleated.

A specimen of the tumour was taken immediately and tissue cultured (Sevel, Sealy and Lawton, 1973). The sensitivity of the retino-blastoma to specific cytotoxics in vitro was assessed. There was no inhibition of retinoblastic cell growth against Endoxan and Mustine. Against Vincristine alone, there was moderate inhibition of retinoblastic cell growth. Against Vincristine plus Endoxan there was the most inhibition. 
Postoperative treatment included deep $x$-ray therapy to a maximum tumour dose of 3695 rads over 29 days and six injections each of Endoxan ( $75 \mathrm{mg}$.) and Vincristine $(275 \mathrm{mg}$.) at intervals of I week.

\section{Result}

The patient has been assessed at regular intervals since the completion of treatment. On June I I, I973, it was found that the left socket was contracted but free of tumour. There was no draining lymphadenopathy. The right fundus showed an active retinoblastoma which was not responding to deep $x$-ray therapy and cytotoxic treatment, but there was no extension into the vitreous.

\section{Histological examination}

MACROSCOPIC

The eye was $2 \mathrm{~cm}$. in diameter and the optic nerve stump $0 \cdot 4 \mathrm{~cm}$. long. A white granular tumour mass filled the entire vitreous body. The anterior chamber was not involved by the tumour.

\section{MICR OSCOPIC}

An exoendophytic retinoblastoma had destroyed most of the retina and extended into the vitreous body. Focal invasion of the choroid was noted. The optic nerve was not invaded and the lens, iris, ciliary body, and anterior chamber appeared normal.

Part of the retinoblastoma was undifferentiated with areas of necrosis and calcification. Scattered in this tissue were clusters of well-formed Flexner-Wintersteiner rosettes. Separate from this section of the tumour were areas of loose, spongy tumour tissue in which numerous single cell photoreceptor elements were noted. In addition small well-formed fleurettes were observed (Figs 3 and 4).

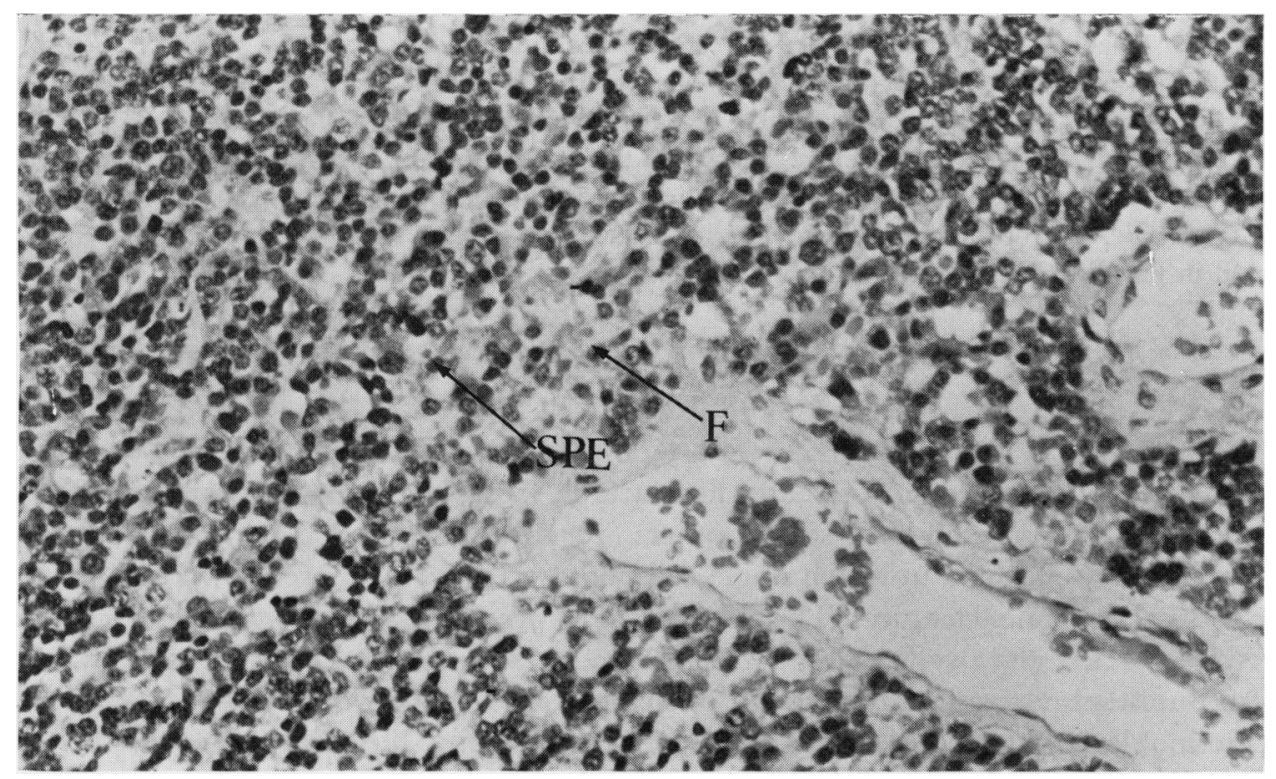

FIG. 3 Case 4. There is a loose spongy appearance to this area of the retinoblastoma. In the intercellular spaces small fleurettes ( $F$ arrow) and single photoreceptor elements (SPE arrow) are seen. Haematoxylin and eosin. $\quad \times 120$

\section{ELECTRON MICROSCOPY}

Tumour tissue was fixed in glutaraldehyde and embedded in epoxy resin. Sections were stained with uranyl acetate and lead acetate.

These showed the ultrastructure of single-cell photoreceptor elements and fleurettes.

Single-cell photoreceptor elements were seen to have a nucleus surrounded by a thin cytoplasmic 


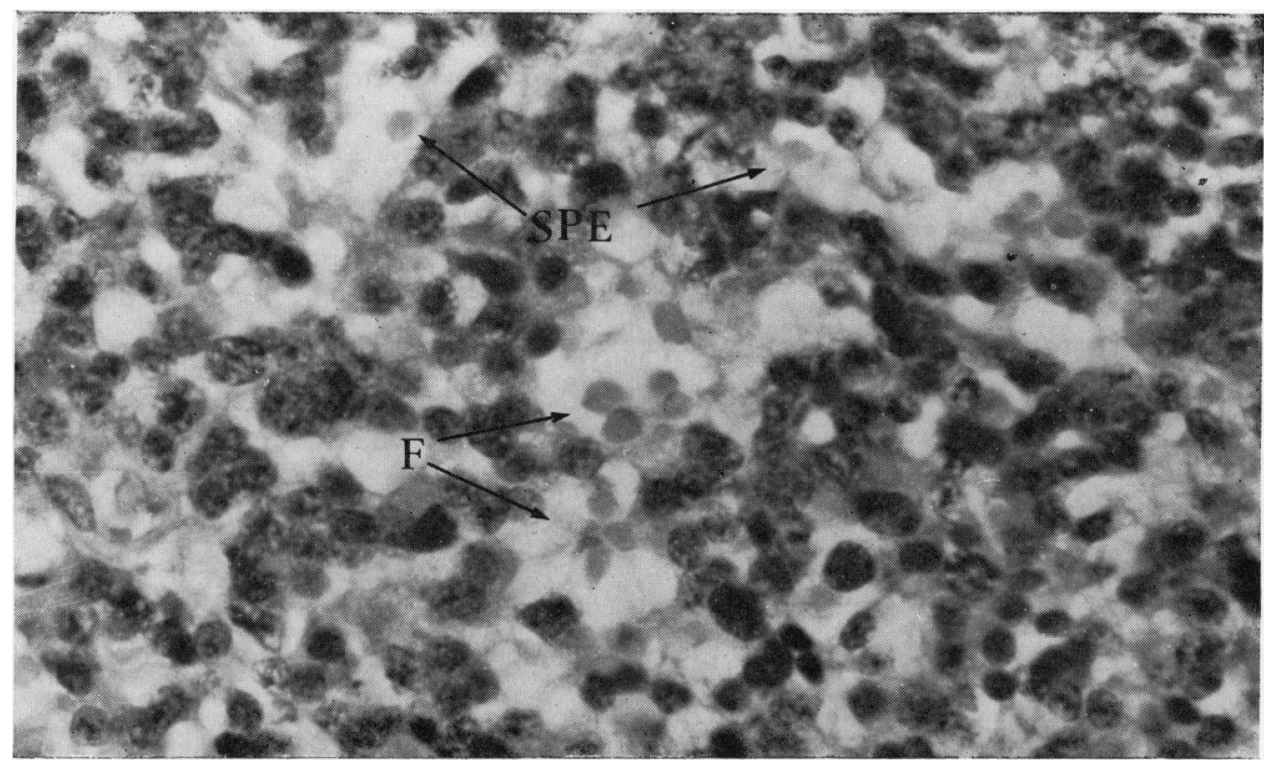

FI G. 4 Case 4. Poorly differentiated small fleurettes ( $F$ arrow) and single photoreceptor elements (SPE arrow) are seen in a spongy area of the retinoblastoma. Haematoxylin and eosin. $\quad \times 300$

layer which was drawn out into a long process. The cytoplasmic extension had numerous neurotubules and towards its tip many large and irregular mitochondria were present. Surrounding tumour cells were closely applied to the photoreceptor cells and intercellular bridges were not present.

The fleurettes (Fig. 5) consisted of a cluster of photoreceptor cell elements with interdigitating cytoplasmic processes, with dense intercellular bridges forming at the sites of contact.

These bridges may have been structures that gave the appearance of a fenestrated membrane on light microscopy. The processes fanned out into the intercellular spaces and their bulbous ends were filled with parallel neurotubules and mitochondria. These were large, irregular, and elongated and orientated in parallel along the length of the processes.

The detailed light and electron microscopy in this case will be described in a further communication.

\section{Discussion}

The incidence of photoreceptor cells and fleurettes in four (6 per cent.) of the total series corresponds to that reported by T'so and others (I970a, b).

Eyes with retinoblastoma in which single-cell photoreceptors or fleurettes were observed had no distinctive clinical features. The average age at presentation was 3 years. Two of the children were males and two females. Two presented with squint, one with leucocoria, and one with buphthalmos and leucocoria. In one case both eyes were involved.

The retinoblastomata were all large and affected most of the retina. Anterior uveal involvement was noted in two of the eyes examined.

The histological examination of the eyes, where single-cell photoreceptor or fleurettes were found, was not distinctive. Rosette formation was noted in one eye and calcification was noted in another.

One patient died 5 months after treatment, one has survived for 5 years, and two have survived so far for 6 months. The prognosis for Case 4 is poor, because the increased radioactive uptake over the frontal region probably indicates intracranial extension of the tumour.

T'so and others (1970a, b) suggested that the presence of fleurettes and photoreceptor 


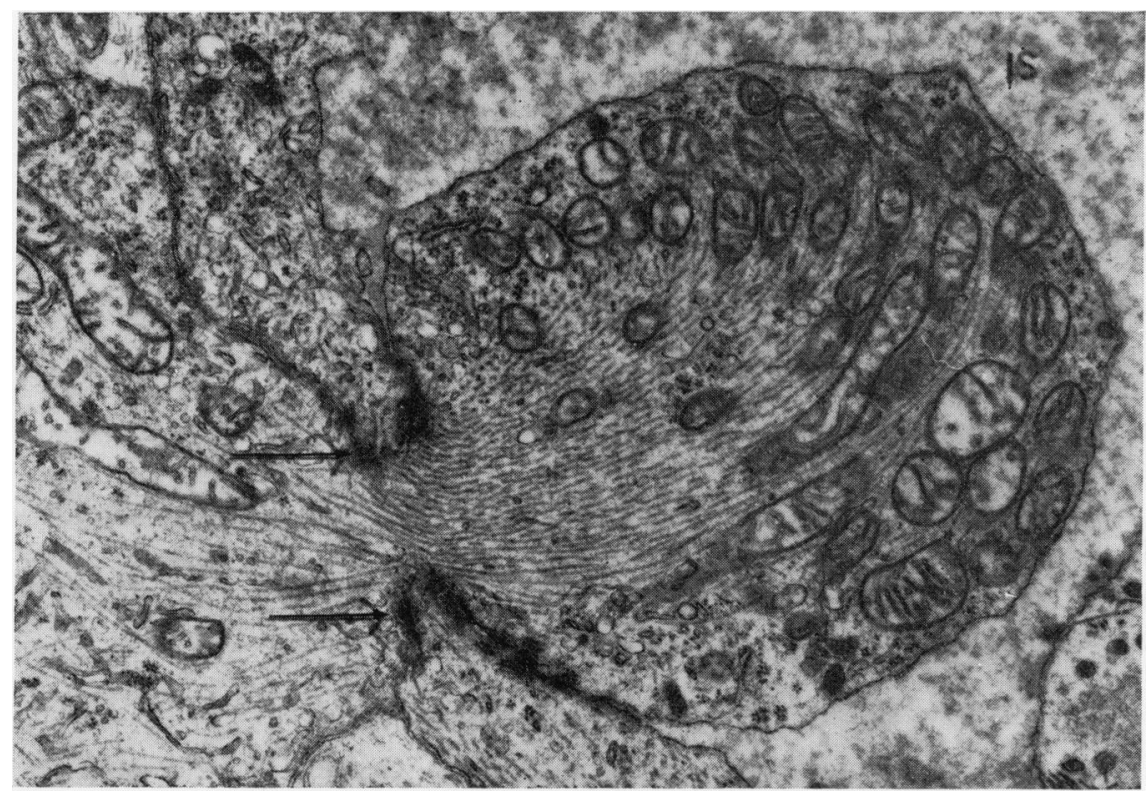

FI G. 5 Case 4. A bulbous inner segment of a fleurette cell projects into an intercellular space (IS). It interdigitates with surrounding cells and at these sites large dark intercellular bridges (arrows) are present. The process is filled with big elongated mitochondria and parallel streams of neurotubules. OSO4/araldite/uranyl/acetate-lead citrate. $\times$ I5,000

elements possibly indicated a better prognosis for retinoblastoma as all their patients survived. This was not found in our series, in which the tumours were clinically and histologically of an advanced and aggressive nature.

It seems unlikely that isolated areas of differentiation within an undifferentiated neoplasm would improve the prognosis.

It is felt that in retinoblastoma fleurettes, photoreceptor elements, and rosettes are morphological arrangements of malignant cells, and from our series seems to show that the presence of single-cell photoreceptors and fleurettes are unlikely to be of clinical or therapeutic prognostic importance.

\section{Summary}

In a series of 67 eyes with retinoblastoma, four ( 6 per cent.) showed, on histological examination, the presence of single photoreceptor cells and fleurettes.

No specific clinical features were found in these eyes and it was not possible to ascribe any prognostic significance to single photoreceptor cells or fleurettes.

We wish to thank Mr.J. R. P. Dale and Mr. M. Emms for technical assistance with the electron microscopy

This investigation was financed by the Gratitude Fund for Ophthalmc logy, the Goosen Trust Fund, and the Department of Ophthalmology Research Fund, Groote Schuur Hospital

\section{References}

Editorial (1973) Lancet, r, 88

SEVEL, D., SEALY, R., and LAWTON, E. (1973) Trans. ophthal. Soc. U.K., 93, 23

T'so, м. о. м., Fine, в. s., and zimmerman, L. E. (1970a) Amer. F. Ophthal., 69, 350

-, zimmerman, L. E., and FiNe, B. s. (1970b) Ibid., 69, 339 